\title{
Nonmedical Prescription Drug Use among U.S. Young Adults by Educational Attainment
}

\author{
Silvia S. Martins, M.D., Ph.D. ${ }^{1}$, June H. Kim, M.H.S. ${ }^{1}$, Lian-Yu Chen, M.D. ${ }^{2}$, Deysia Levin, \\ M.P.H. ${ }^{1}$, Katherine M. Keyes, Ph.D. ${ }^{1}$, Magdalena Cerdá, Dr. Ph. ${ }^{1}$, and Carla L. Storr, Sc.D. ${ }^{3}$ \\ ${ }^{1}$ Department of Epidemiology, Columbia University \\ ${ }^{2}$ Department of Mental Health, Johns Hopkins Bloomberg School of Public Health \\ ${ }^{3}$ Department of Family and Community Health, University of Maryland School of Nursing
}

\begin{abstract}
PURPOSE-Little is known about nonmedical use of prescription drugs among non-college attending young adults in the United States.
\end{abstract}

METHODS-Data was drawn from 36,781 young adults (ages 18-22 years) from the 2008-2010 National Survey on Drug Use and Health public use files. The adjusted main effects for current educational attainment, along with its interaction with gender and race/ethnicity, were considered.

RESULTS-Compared to those attending college, non-college attending young adults with at least and less than a HS degree had a higher prevalence of past-year nonmedical use of prescription opioids (NMUPO: $13.1 \%$ and $13.2 \%$, respectively, vs. $11.3 \%$, adjusted Odds Ratios [aORs]: 1.21 [1.11-1.33] and 1.25 [1.12-1.40]), yet lower prevalence of prescription stimulant use. Among users, regardless of drug type, non-college attending youth were more likely to have past year disorder secondary to use (e.g., NMUPO: $17.4 \%$ and $19.1 \%$, respectively, vs. $11.7 \%$, aORs: 1.55 [1.22-1.98] and 1.75 [1.35-2.28]). Educational attainment interacted with gender and race: 1) among nonmedical users of prescription opioids, females who completed high school but were not enrolled in college had a significantly greater risk of opioid disorder (compared to female college students) than the same comparison for men; and 2) the risk for nonmedical use of prescription opioids was negligible across educational attainment groups for Hispanics, which was significantly different than the increased risk shown for Non-Hispanic whites.

CONCLUSIONS-There is a need for young adult prevention and intervention programs to target nonmedical prescription drug use beyond college campuses.

\section{Keywords}

nonmedical prescription drug use; drug use disorders; educational attainment; young adults; gender differences

Address correspondence to: Silvia S. Martins, Department of Epidemiology, Mailman School of Public Health, 722 West $168^{\text {th }}$ Street, Rm. 509, New York NY, 10032, [ ssm2183@ columbia.edu], 212-305-2848/410-929-9303.

Disclosure: Dr. Martins is currently a consultant for Purdue Pharma. All other authors have no conflict of interest to declare. 


\section{Introduction}

Nonmedical prescription drug use - use without a prescription or use with a prescription but in a manner other than how prescribed - is the fastest growing drug problem in the United States [1], driven primarily by nonmedical use of prescription opioids (NMUPO) among younger cohorts [2]. While a large proportion of young adults (age 18-22) are prescribed opiates (PO) and stimulants for legitimate health conditions [3-7], NMUPO is second only to marijuana as the most prevalent form of illegal drug use among young adults, and a third of persons with opiate disorders secondary to PO use in 2011 were young adults [8]. Nonmedical use of prescription stimulants is also of concern among young adults [5-7,9]. Moreover, this age group is particularly vulnerable to the development of adverse substance using patterns, due in part to the process of identity formation that emerges at this developmental stage, and a greater level of independence compared to adolescence [10].

A limitation of many studies on nonmedical prescription drug use (particularly opiates) among young adults is that their samples are limited to select segments of the young adult population. For example, a few studies have examined NMUPO in community samples of high-risk young adults (i.e., injection drug users) in urban settings, but none of these studies have compared estimates to young adults in the general population [11-16]. Problems related to substance use on college campuses has also been a central focus of research on alcohol [17,18], nonmedical stimulant use [5-7,19-22], and NMPO [7,23,24] use among college students. However, many young adults are not seeking a college education [25]. It has been estimated that among those completing their secondary education, about $70 \%$ enroll in further education: $42 \%$ enroll in 4-year institutions and $28 \%$ at 2-year institutions right after graduating high school [26]. College-based studies also exclude significant proportions of minority young adults [27]. The National Center for Education Statistics indicates that high school dropout rates are particularly high for non-Hispanic (NH) black and Hispanic students, as well as for those who are the first in their family to attend college, and those who have limited English proficiency [28]. Nationally, about $75 \%$ of all students graduate from high school on time with a regular diploma, but barely half of non-Hispanic black and Hispanic students earn diplomas with their peers [29]. Thus, a substantial proportion of young adults fall outside the purview of college-based studies and there is a need to further compare the prevalence of nonmedical prescription use of opiates and stimulants and disorders secondary to their use by race/ethnicity between young adults who attend college versus those that do not attend college. Notably, most prevention programs to reduce substance use among young adults are designed for college settings; a comparison between college- and non-college attending young adults would illuminate specific issues that need to be adapted for prevention programs targeting non-college attending youth [30].

It is also important to investigate whether there are any racial/ethnic and male-female differences in NMUPO or nonmedical stimulant use within sub-groups of young adults with similar educational attainment levels. Lifetime and past-year drug use disorders have been consistently associated with lower educational attainment and minority status [31-35]. Studies suggest that individuals with less years of formal education are at high risk of becoming drug dependent $[32,34]$ and of experiencing persistent dependence, in contrast to those with more years of formal education [34]. Among college students, whites are more 
likely than students of other race/ethnicities to be nonmedical stimulant and prescription opioid users $[5,7,23,24,36,37]$. The evidence on potential gender differences in nonmedical prescription drug use among young adults has been mixed -- some studies find no difference, others have found a higher prevalence in males, and others in females [7,8,23,24,36-39]. Very few studies have investigated male-female differences in prescription stimulant and prescription opioid disorders secondary to nonmedical use in young adults $[40,41]$. Thus, examining how college attendance modifies gender differences might inform the mixed results on the association between gender and nonmedical prescription drug use. This study aims to examine racial/ethnic and male-female differences in nonmedical prescription use of opiates and stimulants as well as on disorders secondary to their use among young adults by different educational attainment.

The goals of this study are to explore whether nonmedical prescription drug use (specifically, opioids and stimulants) and disorders secondary to the drug use varies by education and examine race/ethnic and male-female differences within educational subgroups using data obtained from nationally representative samples of 18-22 year olds residing in the United States. Specifically, we sought to: (1) compare the 12-Month prevalence of nonmedical use of prescription opioids and stimulants as well as the prevalence of opioid and stimulant disorder secondary to nonmedical use among noncollege-attending young adults versus their college attending peers adjusting for demographics and past-year serious psychological distress, and (2) test for risk differences of nonmedical use and disorder among males and females separately and racial/ethnic groups stratified by educational attainment in this population. Our models also adjust for the presence of psychological distress because POs have been found to be used nonmedically to self-medicate negative emotions among young adults [42] and several studies have shown that NMUPO can be related to psychological distress in general population samples [43-48].

\section{Materials and Methods}

\section{Study sample and measures}

We analyzed data from 36,781 young adults between the ages of 18-22 from the 2008 $(\mathrm{n}=57,739), 2009(\mathrm{n}=55,772)$, and $2010(\mathrm{n}=57,873)$ NSDUH public use files; three consecutive NSDUH years were combined in order to increase sample size. The NSDUH is an annual cross-sectional survey sponsored by the Substance Abuse and Mental Health Administration (SAMHSA) and is designed to provide estimates of the prevalence of drug use and disorders in the household population of the United States among those 12 years old and older [49]. Annually the survey selects an independent multistage area probability sample for each of the 50 states and the District of Columbia. African-Americans, Hispanics, and young people were over-sampled to increase the precision of estimates for these groups. The response rate for household screening was $88 \%$ and the weighted response rate was $74.8 \%$ for completed interviews across the three years [50]. Survey items were administered by computer-assisted personal interviewing (CAPI) conducted by an interviewer and audio computer-assisted self-interviewing (ACASI). Use of ACASI was designed to provide respondents with a highly private and confidential means of responding to questions and to increase the level of honest reporting of drug use and other sensitive 
behaviors [51]. Respondents were offered a $\$ 30$ incentive payment for participation in the survey. Detailed information about the sampling and survey methodology of NSDUH are found elsewhere [8,35,49]. All respondents provided information about their drug experiences and their socio-demographic characteristics. The NSDUH questionnaire instrument has sensitivity values ranging from $0.8-0.97$ for most substances, and specificity values of $0.7-0.95[35,52]$.

\section{Outcome variables: nonmedical prescription opiate and stimulant use and disorders secondary to use}

NMUPO was defined as any self-reported use of prescription pain relievers that were not prescribed for the respondent or that the respondent took only for the experience or feeling they caused [49]. In order to reduce false-positive responses, all respondents were given the following instructions: "These questions are about prescription pain reliever use. We are not interested in your use of over-the-counter pain relievers that can be bought in stores without a doctor's prescription." Past-year NMUPO was defined based on the response to the following question: 'how long has it been since you last used any prescription pain reliever that was not prescribed for you or that you took only for the experience or feeling it caused.' If the respondent answered positively, they were classified as a lifetime NMUPO user. Then, if the response indicated that nonmedical use occurred during the preceding 12 months, the respondent was classified as a past-year NMUPO user. The survey used discrete questions and a card with pictures of many types of prescription opioids. The respondents were asked which ones he/she had used, as well as frequency of use.

Similarly, the NSDUH used a screening question that assessed whether the respondent had ever used a prescription stimulant that was not prescribed, or taken one for the experience or feeling it caused. If the response was positive, the respondent was given a card with pictures of many types of prescription stimulant sand was asked which ones he/she had used, as well as frequency of use. Then, if the response indicated that nonmedical use occurred during the preceding 12 months, the respondent was classified as a past-year prescription stimulant user.

Respondents with NMUPO in the past-year were asked a set of 17 structured questions designed to operationalize DSM-IV criteria [53] for past-year opioid abuse and dependence secondary to NMUPO (referred together as OD secondary to NMUPO in this manuscript).

Similar questions were asked to operationalize DSM-IV criteria [50] for past-year stimulant abuse and dependence secondary to prescription stimulant use (referred together as prescription stimulant disorder in this manuscript).

\section{Primary exposure variable: Educational attainment}

Current educational attainment was operationalized in the NSDUH as: 1) current college student, 2) high school graduate/GED [general education certification], 3) did not complete high school (this information was only asked for 18-22 year-old respondents). There was no information on whether respondents were attending 2-year (community colleges) or 4-year colleges. 


\section{Demographic covariates}

Demographic variables selected for this study included gender, race/ethnicity (non-Hispanic white, non-Hispanic African American, Native American/Hawaiian/Pacific Islander, Asian, more than one race, Hispanic), and whether they resided in a large metro, small metro or nonmetropolitan statistical area. We recognize that for some racial/ethnic groups sample sizes of respondents (particularly for disorders) will be small, but simply combining these groups into an "Other" group would prohibit us from exploring potential prevalence disparities that might exist.

\section{Past-year serious psychological distress}

Serious psychological distress (SPD) was measured using the Kessler 6 (K6) screening instrument for nonspecific psychological distress. The K6 scales were designed to maximize the ability to discriminate cases of SPD from non-cases [54]. The tool consists of 6 items, each with a $0-4$ point rating scale that screens for general distress in the past year. It has excellent internal consistency and reliability (Cronbach's alpha $=0.89$ ). In all years respondents were classified with past-year SPD if the totaled summed score was 13 or greater [54].

\section{Statistical analyses}

Data were weighted to reflect the complex design and multiple years of the NSDUH sample and were analyzed using Stata 11.0 [55] and SUDANN [59] software (specifically used for interaction-testing). We used Taylor series estimation methods to obtain proper standard error estimates for the cross-tabulations and logistic regressions. All percentages reported are weighted by study weights. Because we analyzed data from three NSDUH years combined, weights were divided by three (numbers of years of data combined) as recommended by SAMHSA [8]. Exploratory data analyses did not show any statistically significant differences in the NSDUH samples across years, justifying combining the data from multiple years. After basic contingency tables were created, we ran logistic models that included covariates (adjusted for demographics and past-year serious psychological distress) to compare the prevalence of past-year NMUPO, past-year nonmedical prescription stimulant use, past-year OD secondary to NMUPO, and past-year stimulant dependence secondary to nonmedical prescription stimulant use among college students aged 18-22 versus their non-college student counterparts. Then, we tested for interactive effects between educational group status with both gender and race. Interaction was assessed on the additive scale by testing the interaction contrast (IC), which represents the difference in risk differences [56]. Adjusted ICs were calculated using the PRED_EFF command in SUDAAN [57].

\section{Results}

\section{Estimated past-year prevalence by educational attainment (Table 1)}

The prevalence estimates of past-year NMUPO among 18-22 year-old college students, those with high school diploma/GED and those with less than high school education were $11.3 \%, 13.1 \%$ and $13.2 \%$, respectively. Those with less than high school (aOR: 1.25 [1.12- 
1.40]) and those who completed high school/GED (aOR: 1.21 [1.11-1.33]) were more likely than college students to be past-year NMUPO (Table 1). Women were less likely than men to be past-year NMUPO (aOR: 0.74 [0.68-0.81]); NH blacks, NH Asians and Hispanics were less likely to use PO nonmedically in the past-year compared to $\mathrm{NH}$ whites; and respondents who reported past-year serious psychological distress were more likely than those without distress to report past-year NMUPO (aOR: 2.09 [1.89-2.31]). There were no differences in the prevalence of NMUPO or in the prevalence of OD secondary to NMUPO by county type.

In contrast, the prevalence estimates for past-year nonmedical stimulant use among 18-22 year-old college students, those with a high school diploma/GED, and those with less than high school education were $4.8 \%, 3.1 \%$, and $3.0 \%$, respectively. Those with less than high school (aOR: 0.66 [0.54-0.80]) and those who completed high school/GED (aOR: 0.65 [0.55-0.77]) were less likely to have been past-year nonmedical stimulant users compared to their college-attending peers (Table 1). As with prescription opioids, females, NH blacks, NH Asians, and Hispanics were less likely to report past-year nonmedical stimulant use, and respondents who reported past-year serious psychological distress were more likely than those without distress to report past-year nonmedical stimulant use.

Among young adults aged 18-22 year-old with past-year NMUPO, those with lower educational attainment (less than high school education: 19.1\%, aOR: 1.75 [1.35-2.28], completed high school/GED: 17.4\%, aOR: 1.55 [1.22-1.98]) were more likely to have pastyear OD compared to college students (Table 1). NH blacks were less likely than NH whites to have OD (aOR: $0.60[0.41-0.89]$ ), but there were no racial/ethnic differences in the prevalence of OD between NH whites and those of other racial/ethnic groups. NMUPO users who reported past-year psychological distress were more likely to have OD than those with no psychological distress (aOR: 3.05 [2.40-3.88], Table 1).

Among young adults with past-year nonmedical stimulant use, a similar pattern with educational attainment was seen. Past-year stimulant use disorder was more likely among those with lower educational attainment (less than high school education: 17.9\%, aOR: 2.39 [1.35-4.12], completed high school/GED: 14.0\%, aOR:1.75 [1.02-3.02]) compared to their college attending peers (Table 1). However, among past-year nonmedical stimulant users, NH Asians were more likely than whites to have developed past-year stimulant use disorder (aOR: 3.29 [1.17-9.24]), and those living in a non-metro county type were less likely to develop past-year stimulant use disorder (aOR: 0.54 [0.32-0.92]), compared to living in a large metro area.

\section{Risk differences: educational attainment by gender (Table 2)}

For both males and females, having less than a high school degree was associated with a greater risk of NMUPO use compared to their college attending counterparts (RD: 3.4\%, p<. 001 for males, RD: $1.5 \%, \mathrm{p}=0.072$ for females). While a greater risk difference was observed for males, this association was not significantly different from that of females (IC: $2.0 \%, \mathrm{p}=0.069)$. Further, the relationship between educational attainment and past-year OD among PO users differed by gender. While the difference between male college students and males with a high school diploma/GED for past-year OD secondary to NMUPO was 
negligible (RD: 1.7\%, $\mathrm{p}=0.445)$, females with a high school diploma/GED had a much greater risk compared to their college-attending counterparts (RD: 8.2\%, p<.001). In our test of additive interaction, the risk of OD secondary to NMUPO associated with educational attainment did significantly differ by gender (IC: $-6.5 \%, \mathrm{p}=0.050$ ). For past-year nonmedical stimulant use, females with less than a high school degree were significantly less likely to report past-year nonmedical stimulant use than females with college education (RD: $-2.2 \%, \mathrm{p}<.001)$. There was less of an educational risk difference among males (RD: $-0.8 \%, \mathrm{p}-0.080)$.

\section{Risk differences: educational attainment by race (Table 3)}

The relationship between educational attainment and NMUPO was modified by race. Among $\mathrm{NH}$ whites, those with lower educational attainment had a significantly higher risk of NMUPO compared to college students (completed high school/GED, RD: 2.7\%, p<.001; less than a high school (HS) degree, RD: 3.0\%, p<.001). However, among Hispanics, NH blacks, $\mathrm{NH}$ more than one race and Asians there were no significant differences between either of the lower educational attainment groups and college students for risk of NMUPO (see Table 3). The risk differences for Hispanic groups were significantly different from those observed for their $\mathrm{NH}$ white counterparts (IC: $-3.2 \%, \mathrm{p}=0.031$, IC: $-3.0 \%, \mathrm{p}=0.040$, for completed HS/GED and less than a HS degree, respectively). Further, while the risk of NMUPO associated with educational attainment was much more pronounced among Native Americans/Pacific Islanders and Asians, these risk differences were not significantly different from those observed for their NH white counterparts. For past-year OD among NMUPO, the risk associated with educational attainment did not significantly differ by race.

For past-year nonmedical stimulant use, the risk differences between $\mathrm{NH}$ whites attending college compared to $\mathrm{NH}$ whites with less than a high school diploma (RD: $-2.2 \%, \mathrm{p}<.001$ ) and NH whites with a high school diploma/GED (RD: -2.4, p<.001), was significantly greater than the same educational attainment comparisons among NH blacks (for less than high school degree, IC: $1.9 \%, \mathrm{p}=0.002$; for at least a high school diploma/GED, IC: $2.2 \%$, $\mathrm{p}<.001$ ) and among Hispanics (for less than high school degree, IC: $1.4 \%, \mathrm{p}=0.031$; for at least a high school diploma/GED, IC: $2.5 \%, \mathrm{p}=0.004)$. For past-year stimulant use disorder among past-year stimulant users, the risk associated with educational attainment did not significantly differ by race.

\section{Discussion}

Findings from the study highlight the need to examine in greater detail the determinants of NMPO and both prescription stimulant and opioid disorders among young adults who are not in college. Past-year prevalence rates of NMUPO and OD secondary to NMUPO are higher in these subpopulations than among college students. These findings are in sharp contrast with the educational profile of nonmedical stimulant users in this age group. Consistent with reports from other studies [37,58,59], past-year prevalence of nonmedical prescription stimulant use is higher among college-attending young adults than among those that do not attend college. On the other hand, similar to our prescription opioid disorders findings, prescription stimulant disorders were more prevalent among nonmedical 
prescription stimulant users who were non-college attending young adults as compared to their college-attending peers. These findings are in line with several other studies (with a focus on other substances) suggesting that individuals with lower levels of educational attainment are at high risk of developing drug use disorders $[34,32,60]$. It is important to note that over $40 \%$ of the nonmedical PO and stimulant users identified in the National Epidemiologic Survey on Alcohol and Related Conditions (NESARC) data who initiated use of these drugs at 18 years of age or younger went on to develop prescription opioid and stimulant disorders [61]. Previous studies have already shown that users with more years of formal education tend to mature out of using drugs and may have more resources to seek help and reestablish their life again after becoming drug-involved, while that is often not the case among populations with fewer years of formal education $[62,63]$.

Despite the fact that women were less likely than men to be past-year NMUPO, they were equally likely as men to have OD secondary to NMUPO. These findings are consistent with findings from general population studies [40]. Interestingly, the relationship between educational attainment and OD among NMUPO was modified by gender. An important finding of this study is that among NMPO users, women with less years of formal education are at significantly higher odds to progress to OD secondary to NMUPO, but this same risk was not observed in males. There was only weak evidence of a gender and educational attainment interaction among stimulant users. Prevention messages targeting women aged 18-22 who have high school degrees but are not attending college and using POs are needed in order to prevent escalation to OD.

Also noteworthy is that among $\mathrm{NH}$ whites, having lower educational attainment was strongly associated with increased risk of NMUPO. However, among Hispanic young adults, all educational groups had similar low risk for NMUPO. That is, having a college education protects against NMUPO among NH whites but not among Hispanics. This is consistent with prior studies that show that NMUPO is more prevalent in rural regions of the U.S with a large proportion of $\mathrm{NH}$ whites where young adults have lower educational attainment and fewer returns on academic investment [64-67]. Associations between educational attainment and disorders among past year users of either nonmedical prescription opiate or stimulants did not significantly differ by race.

This study shows that, at least among young adults aged $18-22$, the PO epidemic is not simply a phenomena occurring among NH whites in the US. While in this age group minorities seem to be less likely to use POs nonmedically than NH whites, past-year prevalence of OD among users is similar among Hispanics, Native-Americans, Asians, NH of more than one race and $\mathrm{NH}$ whites. There is evidence from other studies that young adults from $\mathrm{NH}$ white racial/ethnic groups could be particularly vulnerable to the consequences of having an OD. Data from national studies and from a sample of Midwestern college students indicate that Hispanics and $\mathrm{NH}$ whites are more likely to engage in NMUPO than $\mathrm{NH}$ blacks, and they are more likely to be recent-onset opioid users than NH blacks $[68,69,43,70]$. Patterns of persistent NMUPO use among Hispanics may be more severe than among NH whites: an analysis of NSDUH 2002-2003 data showed that Hispanics who recently began using PO nonmedically were almost two times more likely to persist using these drugs compared with NH whites [46]. Finally, recent urban data on PO overdose 
mortality points to an increasing risk among Hispanics: while the rate of unintentional PO poisoning mortality increased $6 \%$ among $\mathrm{NH}$ blacks and $8 \%$ among $\mathrm{NH}$ whites in New York City in 2005-2009, the rate increased $75 \%$ among Hispanics in the same time period [71].

These findings have some strong implications as there are few NMUPO prevention programs tailored for young adults with less years of formal education-most prescription drug use prevention messages are targeted towards college students [30]. As such, prevention programs are also needed for non-college attending young adults, not only at the media level, but also in workplaces and other sites that young adult congregate. One of the few prevention programs designed to prevent nonmedical use of prescription drugs is a webbased workplace program, the SmartRx [72] that has been tested among working women (mean age 44 years), but not specifically among large diverse samples of young adults. The program provides the pharmaceutical properties of the medications, instructions on the safe administration of the medications, and alternatives to medications with suggestions on ways to enhance users' health and well-being [72]. Secondary prevention efforts should target non-college attending young adults to prevent the transition from nonmedical use to disorder among young adults who are already nonmedical prescription opioid and prescription stimulant users.

Limitations are noted. While large epidemiologic datasets are useful for examining factors associated with nonmedical prescription opioid use and prescription opioid disorder, we can at most infer associations using the cross-sectional design of this study. The surveys were based on self-report, but the use of computerized reporting system minimizes the impact of social desirability bias on reporting [73]. NSDUH data does not distinguish whether respondents were attending 2-year (community colleges) or 4-year colleges, which could potentially influence findings and needs to be further investigated in future studies. In addition, reasons males do not attend college versus reasons for females not to attend college might be different [74], and these differences might be associated with the development of nonmedical prescription drug use and disorders. Also, we could not distinguish whether these nonmedical prescription opioid users first started using these drugs when legitimately prescribed (e.g., pain relief) or when obtained illegally (e.g., to get high); such data were unavailable in the NSDUH. Moreover, another limitation of the NSDUH data is the fact that motives for use are not included in the questionnaire [75-77]. In addition, the lack of detailed data on psychiatric diagnosis is a limitation of the NSDUH data, as the K-6 scale is a proxy for psychological distress and does not reflect psychiatric diagnoses per se. Gathering such data in future studies will help us understand the profiles of these users, which may be distinct. Small cell sizes for some racial/ethnic groups, particularly when examining disorders, are a limitation. However, this study has also had several substantial strengths, including the rigorous NSDUH research design and data collection methods, large sample size and generalizability to the U.S young adult household population.

In conclusion, this study illustrates that young adults who do not attend college are at particularly high risk for nonmedical prescription opioid use and disorder. In contrast, the nonmedical use of prescription stimulants is higher among college-educated young adults. The influences of gender and race on these associations are important to consider. Higher 
education may be a protective factor for some race/ethnic groups but not for others. There is a need for young adult prevention and intervention programs to target nonmedical prescription drug use beyond college campuses.

\section{Acknowledgments}

The data reported herein come from the National Survey of Drug Use and Health (NSDUH) public use files and made publicly available by the Substance Abuse and Mental Health Services Administration (SAMHSA). Funding source: This study was partially funded by the National Institute of Drug Abuse-National Institutes of Health (NIDA-NIH grant DA023434, Martins; NIDA-NIH grant K01DA030449, Cerdá; NIDA- NIH T32DA031099, Hasin), the Eunice Kennedy Shriver National Institute of Child and Human Development- National Institutes of Health, (NICHD- NIH grant HD020667, Martins); and the National institute on Alcohol and Alcoholism, National Institutes of Health (NIAAA grant K01AA021511, Keyes). NIDA, NICHD and SAMHSA had no further role in the data analysis or interpretation of results.

\section{References}

1. Office of National Drug Control Policy. Epidemic: Responding to America's Prescription Drug Abuse Crisis. 2011. Retrieved on January 25, 2014 from: http://www.whitehouse.gov/sites/default/ files/ondcp/issues-content/prescription-drugs/rx_abuse_plan.pdf

2. Miech R, Bohnert A, Heard K, Boardman J. Increasing use of nonmedical analgesics among younger cohorts in the United States: a birth cohort effect. J Adolesc Health. 2013; 52 (1):3541.10.1016/j.jadohealth.2012.07.016 [PubMed: 23260832]

3. Boyd CJ, Esteban McCabe S, Teter CJ. Medical and nonmedical use of prescription pain medication by youth in a Detroit-area public school district. Drug Alcohol Depend. 2006; 81 (1):3745.10.1016/j.drugalcdep.2005.05.017 [PubMed: 16040201]

4. McCabe SE, West BT, Wechsler H. Trends and college-level characteristics associated with the non-medical use of prescription drugs among US college students from 1993 to 2001. Addiction. 2007; 102 (3):455-465.10.1111/j.1360-0443.2006.01733.x [PubMed: 17298654]

5. McCabe SE, Knight JR, Teter CJ, Wechsler H. Non-medical use of prescription stimulants among US college students: prevalence and correlates from a national survey. Addiction. 2005; 100 (1):96106.10.1111/j.1360-0443.2005.00944.x [PubMed: 15598197]

6. McCabe SE, Teter CJ. Drug use related problems among nonmedical users of prescription stimulants: a web-based survey of college students from a Midwestern university. Drug Alcohol Depend. 2007; 91 (1):69-76.10.1016/j.drugalcdep.2007.05.010 [PubMed: 17624690]

7. McCabe SE, West BT, Teter CJ, Boyd CJ. Trends in medical use, diversion, and nonmedical use of prescription medications among college students from 2003 to 2013: Connecting the dots. Addict Behav. 2014; 39 (7):1176-1182.10.1016/j.addbeh.2014.03.008 [PubMed: 24727278]

8. Substance Abuse and Mental Health Services Administration. Results from the 2010 National Survey on Drug Use and Health: Summary of National Findings. Substance Abuse and Mental Health Services Administration, Office of Applied Studies; Rockville, MD: 2011. NSDUH Series H-41, HHS Publication No. (SMA) 11-4658

9. Fortuna RJ, Robbins BW, Caiola E, Joynt M, Halterman JS. Prescribing of controlled medications to adolescents and young adults in the United States. Pediatrics. 2010; 126 (6):1108-1116.10.1542/ peds.2010-0791 [PubMed: 21115581]

10. Stone AL, Becker LG, Huber AM, Catalano RF. Review of risk and protective factors of substance use and problem use in emerging adulthood. Addict Behav. 2012; 37 (7):747-775.10.1016/ j.addbeh.2012.02.014 [PubMed: 22445418]

11. Lankenau SE, Schrager SM, Silva K, Kecojevic A, Bloom JJ, Wong C, Iverson E. Misuse of prescription and illicit drugs among high-risk young adults in Los Angeles and New York. J Public Health Res. 2012; 1 (1):22-30. [PubMed: 22798990]

12. Bruneau J, Roy E, Arruda N, Zang G, Jutras-Aswad D. The rising prevalence of prescription opioid injection and its association with hepatitis $\mathrm{C}$ incidence among street-drug users. Addiction. 2012; 107 (7):1318-1327.10.1111/j.1360-0443.2012.03803.x [PubMed: 22248184] 
13. Silva K, Schrager SM, Kecojevic A, Lankenau SE. Factors associated with history of non-fatal overdose among young nonmedical users of prescription drugs. Drug Alcohol Depend. 2013; 128 (1-2):104-110.10.1016/j.drugalcdep.2012.08.014 [PubMed: 22974490]

14. Roy E, Arruda N, Bourgois P. The growing popularity of prescription opioid injection in downtown Montreal: new challenges for harm reduction. Subst Use Misuse. 2011; 46 (9):11421150.10.3109/10826084.2011.552932 [PubMed: 21370963]

15. Lankenau SE, Teti M, Silva K, Bloom JJ, Harocopos A, Treese M. Patterns of prescription drug misuse among young injection drug users. J Urban Health. 2012; 89 (6):1004-1016.10.1007/ s11524-012-9691-9 [PubMed: 22684424]

16. Lankenau SE, Teti M, Silva K, Jackson Bloom J, Harocopos A, Treese M. Initiation into prescription opioid misuse amongst young injection drug users. Int J Drug Policy. 2012; 23 (1): 37-44.10.1016/j.drugpo.2011.05.014 [PubMed: 21689917]

17. White A, Hingson R. The burden of alcohol use: excessive alcohol consumption and related consequences among college students. Alcohol Res. 2013; 35 (2):201-218. [PubMed: 24881329]

18. Kypri K, Vater T, Bowe SJ, Saunders JB, Cunningham JA, Horton NJ, McCambridge J. Webbased alcohol screening and brief intervention for university students: a randomized trial. JAMA. 2014; 311 (12):1218-1224.10.1001/jama.2014.2138 [PubMed: 24668103]

19. Weyandt LL, Marraccini ME, Gudmundsdottir BG, Zavras BM, Turcotte KD, Munro BA, Amoroso AJ. Misuse of prescription stimulants among college students: a review of the literature and implications for morphological and cognitive effects on brain functioning. Exp Clin Psychopharmacol. 2013; 21 (5):385-407.10.1037/a0034013 [PubMed: 24099359]

20. Garnier-Dykstra LM, Caldeira KM, Vincent KB, O'Grady KE, Arria AM. Nonmedical use of prescription stimulants during college: four-year trends in exposure opportunity, use, motives, and sources. J Am Coll Health. 2012; 60 (3):226-234.10.1080/07448481.2011.589876 [PubMed: 22420700]

21. Hartung CM, Canu WH, Cleveland CS, Lefler EK, Mignogna MJ, Fedele DA, Correia CJ, Leffingwell TR, Clapp JD. Stimulant medication use in college students: comparison of appropriate users, misusers, and nonusers. Psychol Addict Behav. 2013; 27 (3):832-840.10.1037/ a0033822 [PubMed: 24059834]

22. DeSantis AD, Webb EM, Noar SM. Illicit use of prescription ADHD medications on a college campus: a multimethodological approach. J Am Coll Health. 2008; 57 (3):315-324.10.3200/jach. 57.3.315-324 [PubMed: 18980888]

23. Arria AM, Caldeira KM, Vincent KB, O'Grady KE, Wish ED. Perceived harmfulness predicts nonmedical use of prescription drugs among college students: interactions with sensation-seeking. Prev Sci. 2008; 9 (3):191-201.10.1007/s11121-008-0095-8 [PubMed: 18633709]

24. McCabe SE, Teter CJ, Boyd CJ, Knight JR, Wechsler H. Nonmedical use of prescription opioids among U.S. college students: prevalence and correlates from a national survey. Addict Behav. 2005; 30 (4):789-805.10.1016/j.addbeh.2004.08.024 [PubMed: 15833582]

25. Jekielek, S.; Brown, B. The transition to adulthood: Characteristics of young adults ages 18 to 24 in America. Population Reference Bureau, and Child Trends, 1-33. 2005. Retrieved May 25, 2011 from:http://www.prb.org/pdf05/TransitionToAdulthood.pdf

26. Aud, S.; Hussar, W.; Kena, G.; Bianco, K.; Frohlich, L.; Kemp, J.; Tahan, K. The Condition of Education 2011 (NCES 2011-033). National Center for Education Statistics. U.S. Government Printing Office; Washington, D.C: 2011.

27. Heckman JJ, Lafontaine PA. THE AMERICAN HIGH SCHOOL GRADUATION RATE: TRENDS AND LEVELS. Rev Econ Stat. 2010; 92 (2):244-262.10.1162/rest.2010.12366 [PubMed: 20625528]

28. Digest of Education Statistics. Chapter 3: Postsecondary Education. 2010. Retrieved Feb 202012 from http://nces.ed.gov/programs/digest/d10/ch_3.asp

29. Snyder, TD.; Dillow, SA. Digest of Education Statistics 2011 (NCES 2012-001). Institute of Education Sciences. U.S. Department of Education; Washington, DC: 2012.

30. Dennhardt AA, Murphy JG. Prevention and treatment of college student drug use: A review of the literature. Addict Behav. 2013; 38 (10):2607-2618.10.1016/j.addbeh.2013.06.006 [PubMed: 23846178] 
31. Bergen SE, Gardner CO, Aggen SH, Kendler KS. Socioeconomic status and social support following illicit drug use: causal pathways or common liability? Twin Res Hum Genet. 2008; 11 (3):266-274.10.1375/twin.11.3.266 [PubMed: 18498205]

32. O'Brien MS, Anthony JC. Risk of becoming cocaine dependent: epidemiological estimates for the United States, 2000-2001. Neuropsychopharmacology. 2005; 30 (5):1006-1018.10.1038/sj.npp. 1300681 [PubMed: 15785780]

33. Compton WM, Thomas YF, Stinson FS, Grant BF. Prevalence, correlates, disability, and comorbidity of DSM-IV drug abuse and dependence in the United States: results from the national epidemiologic survey on alcohol and related conditions. Arch Gen Psychiatry. 2007; 64 (5):566576.10.1001/archpsyc.64.5.566 [PubMed: 17485608]

34. Grant BF. Prevalence and correlates of drug use and DSM-IV drug dependence in the United States: results of the National Longitudinal Alcohol Epidemiologic Survey. J Subst Abuse. 1996; 8 (2):195-210. [PubMed: 8880660]

35. Substance Abuse and Mental Health Services Administration. Results from the 2009 National Survey on Drug Use and Health: Volume I. Summary of National Findings. Substance Abuse and Mental Health Services Administration, Office of Applied Studies; Rockville, MD: 2010. NSDUH Series H-38A, HHS Publication No. SMA 10-4856

36. Lord S, Downs G, Furtaw P, Chaudhuri A, Silverstein A, Gammaitoni A, Budman S. Nonmedical use of prescription opioids and stimulants among student pharmacists. J Am Pharm Assoc (2003). 2009; 49 (4):519-528.10.1331/JAPhA.2009.08027 [PubMed: 19589764]

37. Johnston, LD.; O’Malley, PM.; Bachman, JG.; Schulenberg, JE. Monitoring the future national survey results on drug use, 1975-2012: Volume 2, college students and adults ages 19-50. Ann Arbor, MI: 2013.

38. Herman-Stahl MA, Krebs CP, Kroutil LA, Heller DC. Risk and protective factors for methamphetamine use and nonmedical use of prescription stimulants among young adults aged 18 to 25. Addict Behav. 2007; 32 (5):1003-1015.10.1016/j.addbeh.2006.07.010 [PubMed: 16920275]

39. Daniulaityte R, Falck RS, Wang J, Carlson RG. Illicit use of pharmaceutical opioids among young polydrug users in Ohio. Addict Behav. 2009; 34 (8):649-653.10.1016/j.addbeh.2009.03.037 [PubMed: 19398164]

40. Becker WC, Sullivan LE, Tetrault JM, Desai RA, Fiellin DA. Non-medical use, abuse and dependence on prescription opioids among U.S. adults: Psychiatric, medical and substance use correlates. Drug and Alcohol Depend. 2008; 94 (1-3):38-47.

41. McCabe SE. Screening for drug abuse among medical and nonmedical users of prescription drugs in a probability sample of college students. Arch Pediatr Adolesc Med. 2008; 162 (3):225231.10.1001/archpediatrics.2007.41 [PubMed: 18316659]

42. Sullivan MD, Edlund MJ, Steffick D, Unutzer J. Regular use of prescribed opioids: association with common psychiatric disorders. Pain. 2005; 119 (1-3):95-103.10.1016/j.pain.2005.09.020 [PubMed: 16298066]

43. Martins, S.; Storrs, C.; Zhu, H.; Chilcoat, H. Trends in recent-onset extramedical opioid analgesic use in the US from 1991 to 2006. 70th College on Problems of Drug Dependence Annual Meeting; San Juan, Puerto Rico. 2009;

44. Martins SS, Fenton MC, Keyes KM, Blanco C, Zhu H, Storr CL. Mood and anxiety disorders and their association with non-medical prescription opioid use and prescription opioid-use disorder: longitudinal evidence from the National Epidemiologic Study on Alcohol and Related Conditions. Psychol Med. 2012; 42 (6):1261-1272.10.1017/s0033291711002145 [PubMed: 21999943]

45. Fischer B, Lusted A, Roerecke M, Taylor B, Rehm J. The prevalence of mental health and pain symptoms in general population samples reporting nonmedical use of prescription opioids: a systematic review and meta-analysis. J Pain. 2012; 13 (11):1029-1044.10.1016/j.jpain. 2012.07.013 [PubMed: 23040158]

46. Dowling K, Storr CL, Chilcoat HD. Potential influences on initiation and persistence of extramedical prescription pain reliever use in the US population. Clin J Pain. 2006; 22 (9):776783.10.1097/01.ajp.0000210926.41406.2c [PubMed: 17057559]

47. Katz C, El-Gabalawy R, Keyes KM, Martins SS, Sareen J. Risk factors for incident nonmedical prescription opioid use and abuse and dependence: results from a longitudinal nationally 
representative sample. Drug Alcohol Depend. 2013; 132 (1-2):107-113.10.1016/j.drugalcdep. 2013.01.010 [PubMed: 23399466]

48. McCabe SE, Cranford JA. Motivational subtypes of nonmedical use of prescription medications: results from a national study. J Adolesc Health. 2012; 51 (5):445-452.10.1016/j.jadohealth. 2012.02.004 [PubMed: 23084165]

49. Substance Abuse and Mental Health Services Administration. Results from the 2008 National Survey on Drug Use and Health: National Findings. Substance Abuse and Mental Health Services Administration, Office of Applied Studies; Rockville, MD: 2009. NSDUH Series H-36, HHS Publication No. SMA 09-4434

50. National Survey on Drug Use and Health. 2008-2010 National Survey on Drug Use and Health: Overview and Summary of Substate Region Estimation Methodology. 2010. Retrieved from: http://www.samhsa.gov/data/NSDUH/substate2k10/Methodology/ NSDUHsubstateMethodology2010.pdf

51. Gfroerer, J.; Eyerman, J.; Chromy, J. Redesigning an ongoing national household survey: Methodological issues. Substance Abuse and Mental Health Services Administration, Office of Applied Studies; Rockville, MD: 2002.

52. Jordan BK, Karg RS, Batts KR, Epstein JF, Wiesen C. A clinical validation of the National Survey on Drug Use and Health assessment of substance use disorders. Addict Behav. 2008; 33 (6):782798.10.1016/j.addbeh.2007.12.007 [PubMed: 18262368]

53. American Psychiatric Association. Diagnostic and Statistical Manual of Mental Disorders. 4. American Psychiatric Association; 2000. DSM-IV-TR®

54. Furukawa TA, Kessler RC, Slade T, Andrews G. The performance of the K6 and K10 screening scales for psychological distress in the Australian National Survey of Mental Health and WellBeing. Psychol Med. 2003; 33 (2):357-362. [PubMed: 12622315]

55. StataCorp. Stata Statistical Software: Release 11. College Station, TX: StataCorp LP; 2009.

56. Rothman, KJ.; Greenland, S.; Lash, TL. Modern Epidemiology. Wolters Kluwer Health/Lippincott Williams \& Wilkins; 2008.

57. Research Triangle Institute. SUDAAN: Professional Software for Survey Data Analysis. 1989

58. Johnston, LD.; O’Malley, PM.; Bachman, JG. Monitoring the Future national survey results on drug use, 1975-2002. Volume 1: Secondary school students. Bethesda, MD: National Institute on Drug Abuse; 2003. (NIH Publication No. 03-5375)

59. Substance Abuse and Mental Health Services Administration. The NSDUH Report: Nonmedical Use of of Adderall@ among Full-Time College Students. Substance Abuse and Mental Health Services Administration; Rockville, MD: 2009.

60. Martins, SS.; Ko, J.; Kuwabara, S.; Clarke, D.; Alexandre, P.; Zandi, P.; Mendelson, T.; Mortensen, PBO.; Eaton, WW. The relationship of adult mental disorders to socioeconomic status, race/ethnicity, marital status, and urbanicity of residence. In: Eaton, WW., editor. Public Mental Health. Oxford University Press; Oxford, UK: 2012. p. 151

61. McCabe SE, West BT, Morales M, Cranford JA, Boyd CJ. Does early onset of non-medical use of prescription drugs predict subsequent prescription drug abuse and dependence? Results from a national study. Addiction. 2007; 102 (12):1920-1930.10.1111/j.1360-0443.2007.02015.x [PubMed: 17916222]

62. Miech R, Chilcoat $\mathrm{H}$. The formation of a socioeconomic disparity: a case study of cocaine and marijuana use in the 1990s. Am J Prev Med. 2007; 32 (6 Suppl):S171-176.10.1016/j.amepre. 2007.02.021 [PubMed: 17543708]

63. Miech R. The formation of a socioeconomic health disparity: the case of cocaine use during the 1980s and 1990s. J Health Soc Behav. 2008; 49 (3):352-366. [PubMed: 18771068]

64. Keyes KM, Cerda M, Brady JE, Havens JR, Galea S. Understanding the rural-urban differences in nonmedical prescription opioid use and abuse in the United States. Am J Public Health. 2014; 104 (2):e52-59.10.2105/ajph.2013.301709 [PubMed: 24328642]

65. Blackwell DL, McLaughlin DK. Do Rural Youth Attain Their Educational Goals? Rural Development Perspectives. 1999; 13 (3):37-44.

66. Roscigno VJ, Crowle ML. Rurality, Institutional Disadvantage, and Achievement/Attainment*. Rural Sociology. 2001; 66 (2):268-292.10.1111/j.1549-0831.2001.tb00067.x 
67. Young AM, Havens JR, Leukefeld CG. A comparison of rural and urban nonmedical prescription opioid users' lifetime and recent drug use. Am J Drug Alcohol Abuse. 2012; 38 (3):220 227.10.3109/00952990.2011.643971 [PubMed: 22211586]

68. Blanco C, Alderson D, Ogburn E, Grant BF, Nunes EV, Hatzenbuehler ML, Hasin DS. Changes in the prevalence of non-medical prescription drug use and drug use disorders in the United States: 1991-1992 and 2001-2002. Drug Alcohol Depend. 2007; 90 (2-3):252-260.10.1016/j.drugalcdep. 2007.04.005 [PubMed: 17513069]

69. McCabe SE, Morales M, Cranford JA, Delva J, McPherson MD, Boyd CJ. Race/ethnicity and gender differences in drug use and abuse among college students. J Ethn Subst Abuse. 2007; 6 (2): 75-95.10.1300/J233v06n02_06 [PubMed: 18192205]

70. Substance Abuse and Mental Health Services Administration. Results from the 2008 National Survey on Drug Use and Health: National Findings. Substance Abuse and Mental Health Services Administration, Office of Applied Studies; Rockville, MD: 2004. NSDUH Series H-28. DHHS Publication No. SMA 05-4062

71. New York City Department of Health and Mental Hygiene. Data Tables. New York, NY: 2011. Opioid Analgesics in New York City: Misuse, Morbidity and Mortality Update.

72. Deitz DK, Cook RF, Hendrickson A. Preventing prescription drug misuse: field test of the SmartRx Web program. Subst Use Misuse. 2011; 46 (5):678-686.10.3109/10826084.2010.528124 [PubMed: 21043788]

73. Turner CF, Ku L, Rogers SM, Lindberg LD, Pleck JH, Sonenstein FL. Adolescent sexual behavior, drug use, and violence: Increased reporting with computer survey technology. Science. 1998; 280 (5365):867. [PubMed: 9572724]

74. Ross, T.; Kena, G.; Rathbun, A.; KewalRamani, A.; Zhang, J.; Kristapovich, P.; Manning, E. Higher Education: Gaps in Access and Persistence Study (NCES 2012-046). Government Printing Office; Washington, DC: 2012.

75. McCabe SE, Boyd CJ, Cranford JA, Teter CJ. Motives for nonmedical use of prescription opioids among high school seniors in the United States: self-treatment and beyond. Arch Pediatr Adolesc Med. 2009; 163 (8):739-744.10.1001/archpediatrics.2009.120 [PubMed: 19652106]

76. McCabe SE, Cranford JA, Boyd CJ, Teter CJ. Motives, diversion and routes of administration associated with nonmedical use of prescription opioids. Addict Behav. 2007; 32 (3):562575.10.1016/j.addbeh.2006.05.022 [PubMed: 16843611]

77. Ghandour LA, El Sayed DS, Martins SS. Prevalence and patterns of commonly abused psychoactive prescription drugs in a sample of university students from Lebanon: an opportunity for cross-cultural comparisons. Drug Alcohol Depend. 2012; 121 (1-2):110-117.10.1016/ j.drugalcdep.2011.08.021 [PubMed: 21924844] 


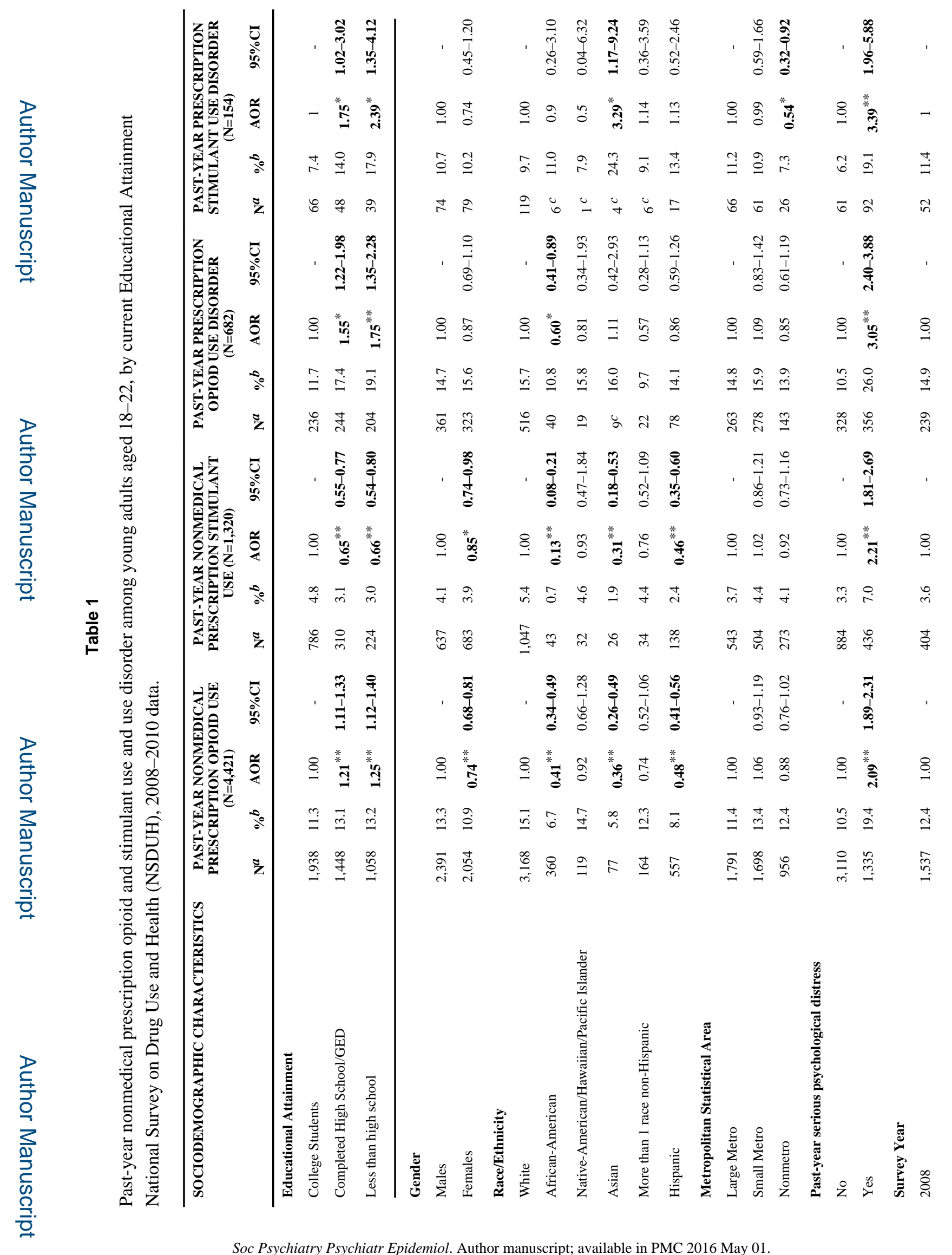




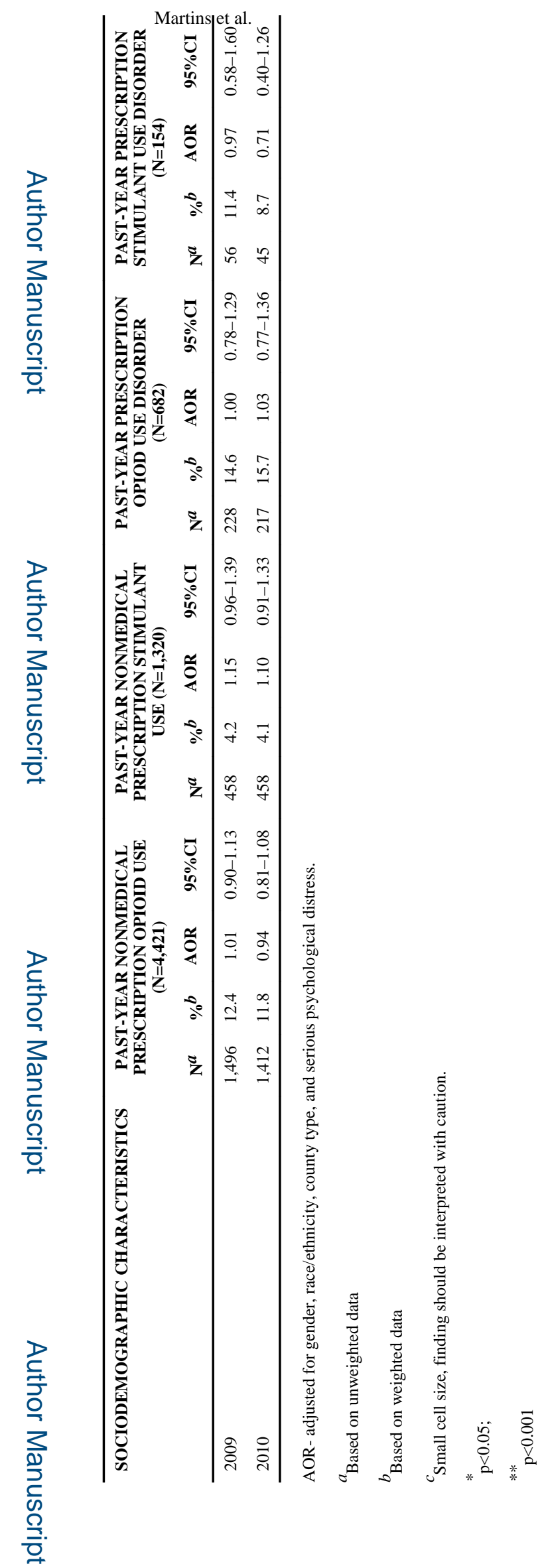

Page 16

Soc Psychiatry Psychiatr Epidemiol. Author manuscript; available in PMC 2016 May 01. 


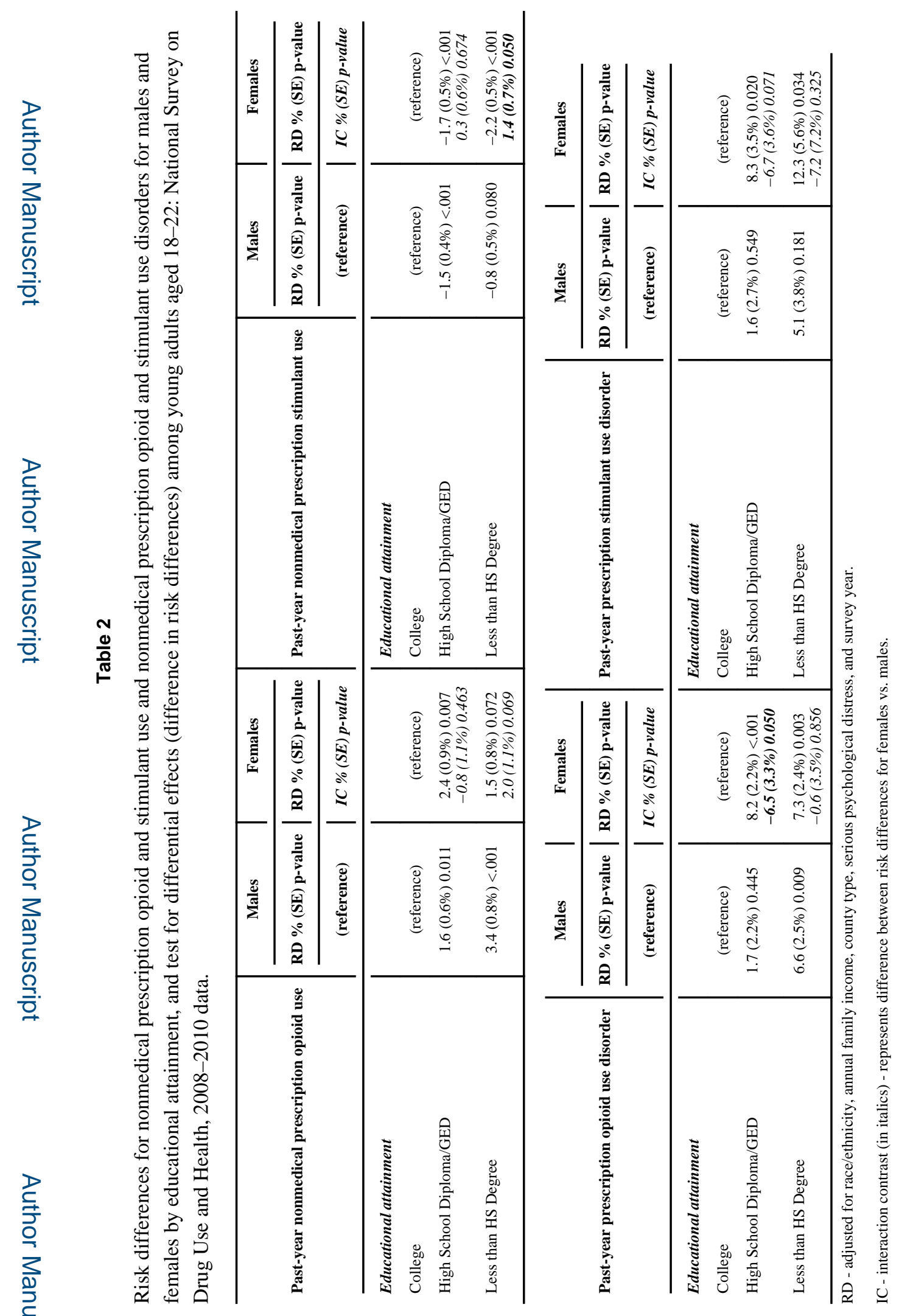

Soc Psychiatry Psychiatr Epidemiol. Author manuscript; available in PMC 2016 May 01. 


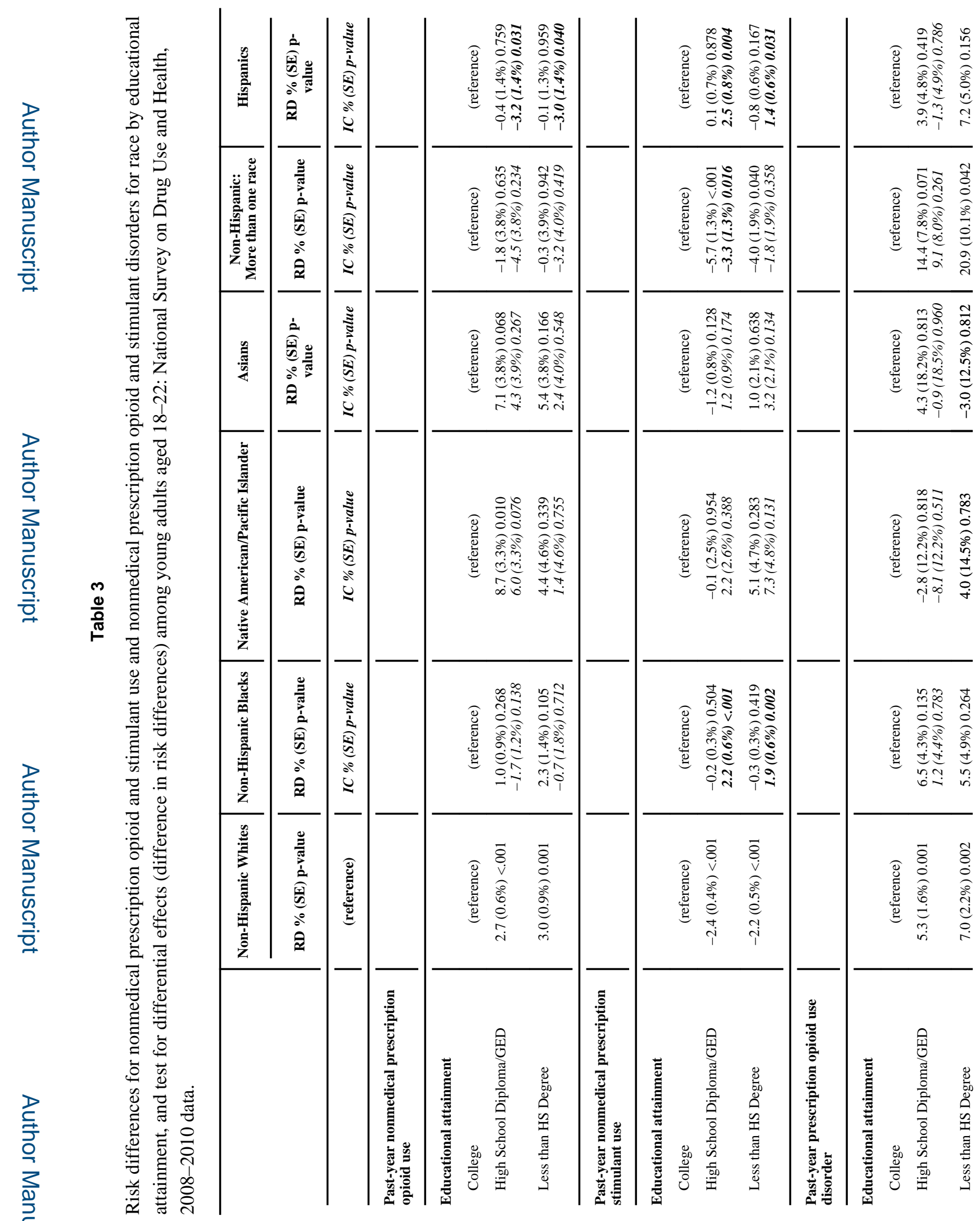

Soc Psychiatry Psychiatr Epidemiol. Author manuscript; available in PMC 2016 May 01. 
Martins et al.

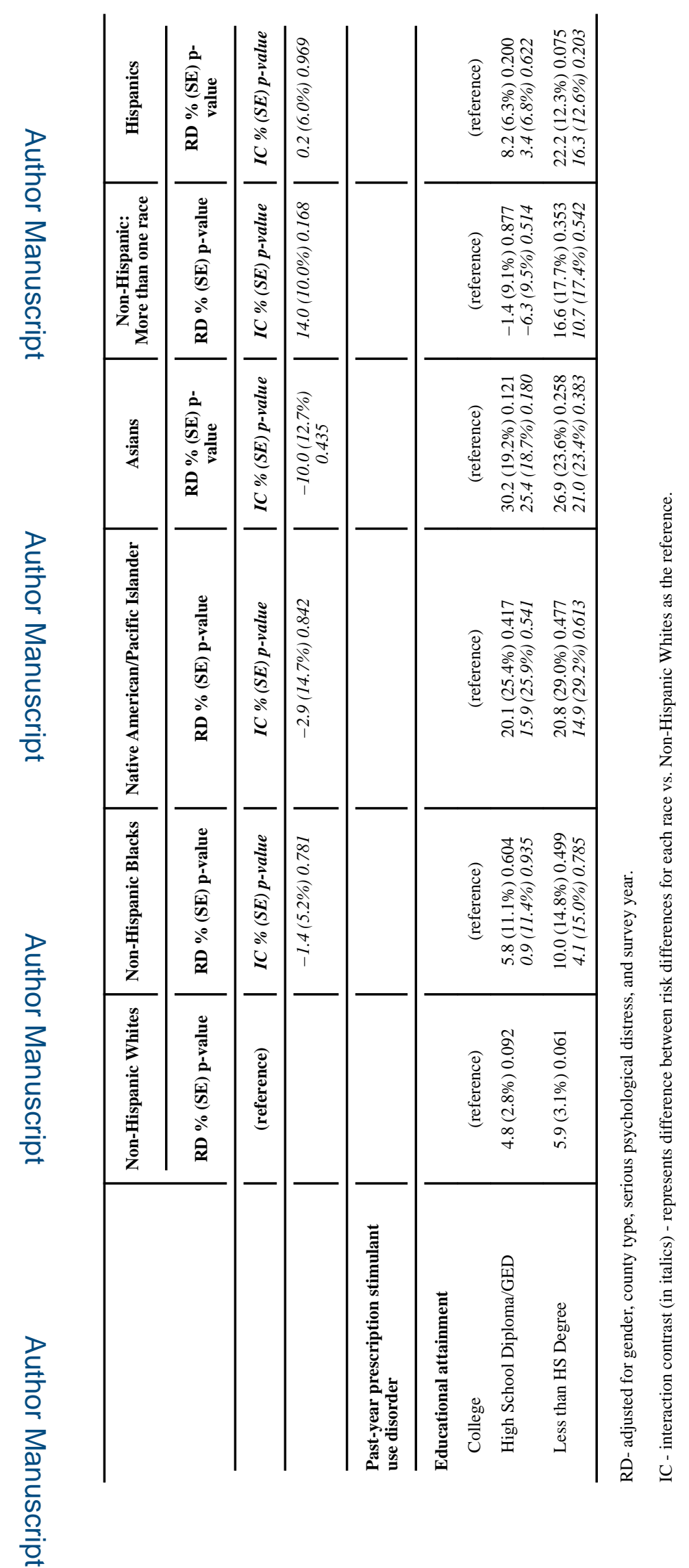

Soc Psychiatry Psychiatr Epidemiol. Author manuscript; available in PMC 2016 May 01. 